\title{
Comparison of hemostatic efficacy and cytotoxicity of three ferric subsulfate- and chitosan-based styptics in different formulations using a rat tail bleeding model
}

\author{
Jae-Young Byun ${ }^{1}$, Soojung Lee ${ }^{2,3}$, Jeong Ik Lee ${ }^{2,3,4}$, Hun-Young Yoon ${ }^{1,2, *}$ \\ Departments of ${ }^{1}$ Veterinary Surgery and ${ }^{4}$ Veterinary Obstetrics and Theriogenology, \\ College of Veterinary Medicine, Konkuk University, Seoul 05029, Korea \\ ${ }^{2}$ Regeniks Co., Ltd. Seoul, Korea \\ ${ }^{3}$ Regenerative Medicine Laboratory, Center for Stem Cell Research, Department of Biomedical Science and Technology, \\ Institute of Biomedical Science and Technology, Konkuk University, Seoul 05029, Korea
}

(Received: May 18, 2018; Accepted: July 12, 2018)

\begin{abstract}
This study was conducted to compare the hemostatic efficacy of three ferric subsulfate- and chitosan-based styptics as a powder and a gel containing ferric subsulfate and chitosan (FSC-PO and FSC-G, respectively) and a soaked pad containing ferric subsulfate and lidocaine (FSL-SP) using a rat tail bleeding model. The cytotoxicity of the styptics against L-929 mouse fibroblasts was also evaluated using a cell counting kit-8 assay. Four groups of 10 rats each were assigned to the three different styptics and a non-treated control groups. Rat tail tips were transected, after which styptics were applied with pressure. The wounds were observed for hemostasis for 3 min, then irrigated with saline to check for recurrent hemorrhage. L-929 mouse fibroblasts were exposed to extracts of the styptics (100 mg/ $\mathrm{mL})$ and their dilutions $(1: 10,1: 100$, and 1:1,000). FSC-PO and FSC-G more effectively controlled initial hemorrhage than FSL-SP $(p=0.033)$. Additionally, FSC-PO and FSC-G more effectively maintained hemostasis than the control group ( $p=0.02$ and $p<0.01$, respectively). However, all styptics showed enhanced cytotoxicity against L-929 cells in a dose-dependent manner. Therefore, although FSC-PO and FSC-G would be recommended to control hemorrhage, the benefits of styptics must be balanced against the clinical significance of their cytotoxicity.
\end{abstract}

Keywords: chitosan, ferric subsulfate solution, hemostasis, hemostatics, immunologic cytotoxicity

\section{Introduction}

Hemorrhage continues to be a leading cause of preventable death in patients with trauma in both human and veterinary medicine [21, 24]. Uncontrolled hemorrhage renders the patient more vulnerable to hypothermia, acidosis, and coagulopathy and increases the risk of morbidity and late mortality from sepsis and multiple organ failure [21].

The traditional theoretical approach to the hemostatic system divides it into primary hemostasis (vasoconstriction and platelet plug formation), secondary hemostasis (coagulation), and fibrinolysis (breakdown of the clot) [5, 27]. Vasoconstriction is the first mechanism of hemostasis controlled by the damaged vascular endothelium, which reduces the blood flow through the affected area and limits the amount of blood loss [5]. Primary hemostasis, the process whereby circulating platelets interact with the vascular surface, results in platelet activation and release of von Willebrand factor, which promotes adherence of platelets to the vessel wall $[10$, 38]. Secondary hemostasis is the process by which coagula- tion factors are activated and greatly enhance fibrin formation [5]. Consequently, blood clots are formed and stabilized [10].

Styptics is a specific locally acting hemostatic agent that works by contracting tissue or blood vessels. As a styptic agent, ferric subsulfate has been widely used for minor surgical procedures or small wounds in dermatology, dentistry, and gynecology in human medicine over the past few years $[32,37]$. It is thought to occlude vessels via protein precipitation through the dual action of its acidity and the oxidizing capacity of its subsulfate group $[11,36]$. It is effective in coagulating blood at the site of skin or mucosal biopsies [36], or it may be used for crown and bridge impressions [12]. Its low $\mathrm{pH}$ resists bacterial contamination [32]. However, ferric subsulfate may cause refractory pigmentation of skin and an inflammatory reaction that may persist for weeks at the site of damage [29].

Poly- $N$-acetyl glucosamine, also known as chitin or chitosan, is a naturally occurring polysaccharide found in the exoskeleton of crustaceans [13, 32]. Chitosan has been widely studied in the biomedical field and found to be highly

*Corresponding author

Tel: +82-2-450-0494, Fax: +82-2-450-3037

E-mail: yoonh@konkuk.ac.kr 
biocompatible, biodegradable, and nontoxic [2]. The hemostatic properties of chitosan involve agglutination of red blood cells as well as vasoconstriction [14, 34]. Numerous studies have demonstrated its effectiveness as a hemostatic agent in controlling arterial and venous hemorrhage, as well as in coagulopathy in patients $[1,7,30]$.

Cell culture systems are convenient, controllable, and repeatable methods to assess the biological response of chemicals [28]. A number of classical in vitro assays using reagents such as thiazolyl blue tetrazolium bromide (MTT assay), lactic dehydrogenase (LDH assay), and tetrazolium salts (WST-8; cell counting kit [CCK]-8 assay), are widely used for the assessment of the cytotoxicity [20]. The CCK-8 assay is the most common in vitro nanotoxicity test and was used in the current study [20]. It detects living cells based on the amount of formazan formed by active mitochondria [28].

Styptics is commonly used in veterinary medicine to stop bleeding from nail and beak trimming, and small wounds on the skin. Although styptic agents are applied directly to the blood vessels or tissues, to the best of our knowledge, there is no published report evaluating the efficacy or cytotoxicity of currently used agents or those under development.

Therefore, the aim of this study was to compare the hemostatic efficacy of three ferric subsulfate- and chitosan-based styptics using a rat tail bleeding model, and evaluate their cytotoxicity against L-929 mouse fibroblasts using the CCK8 assay.

\section{Materials and Methods}

\section{Animals}

Forty Sprague-Dawley female rats weighing 96 to $134 \mathrm{~g}$, aged 4 weeks, were purchased from Orient Bio (Korea) and acclimatized to the environment for 1 week. They were housed individually in cages under constant environmental conditions $\left(23 \pm 2^{\circ} \mathrm{C}\right.$, temperature; $55 \pm 5 \%$ humidity; and 12 -h light/dark cycle) with free access to food and water. This study was reviewed and approved by the Institutional Animal Care and Use Committee of Konkuk University (approval No. KU16186-1 and KU17111-1).

\section{Styptic materials}

As the test substances, three different styptic products for animals that have been currently used or under study were selected. The three types of styptics as a powder and a gel containing ferric subsulfate and chitosan (FSC-PO and FSC$\mathrm{G}$, respectively), and a pad soaked in a solution containing ferric subsulfate and lidocaine (FSL-SP) were used.

\section{In vivo evaluation of hemostatic efficacy}

A previously reported rat-tail bleeding model [6] was used with modifications. The animals were randomly assigned to four groups of 10 rats each as the three different styptics and control groups. The rats were anesthetized by intraperitoneal injections of 40 to $75 \mathrm{mg} / \mathrm{kg}$ ketamine (Yuhan, Korea) and 5 to $10 \mathrm{mg} / \mathrm{kg}$ xylazine (Bayer Korea, Korea). Each rat was placed in sternal recumbency. Tails of rats with a diameter of $2 \mathrm{~mm}$ were transected (Fig. 1A), and $50 \mathrm{mg}$ of each test agent was applied to the wounds with pressure of $0.1 \mathrm{~N}$ using a mechanical push-pull gauge (NK-10; Aliyiqi, China) for 10 sec (Fig. 1B). In the control group, a comparable degree of compression was applied without any styptic. The wounds were observed for initial hemostasis by blotting with Whatman No. 1 filter paper at intervals of $10 \mathrm{sec}$ for up to $3 \mathrm{~min}$ (Fig. 1C). Care was taken to avoid detaching the blood clots formed on the cut surface. Three minutes after complete hemostasis, the wounds were irrigated with $10 \mathrm{~mL}$ lukewarm normal saline for $10 \mathrm{sec}$ to check recurrent hemorrhage. The rats were categorized as having achieved hemostasis or nonhemostasis after the application of pressure, and hemorrhagic or non-hemorrhagic after saline irrigation, respectively.
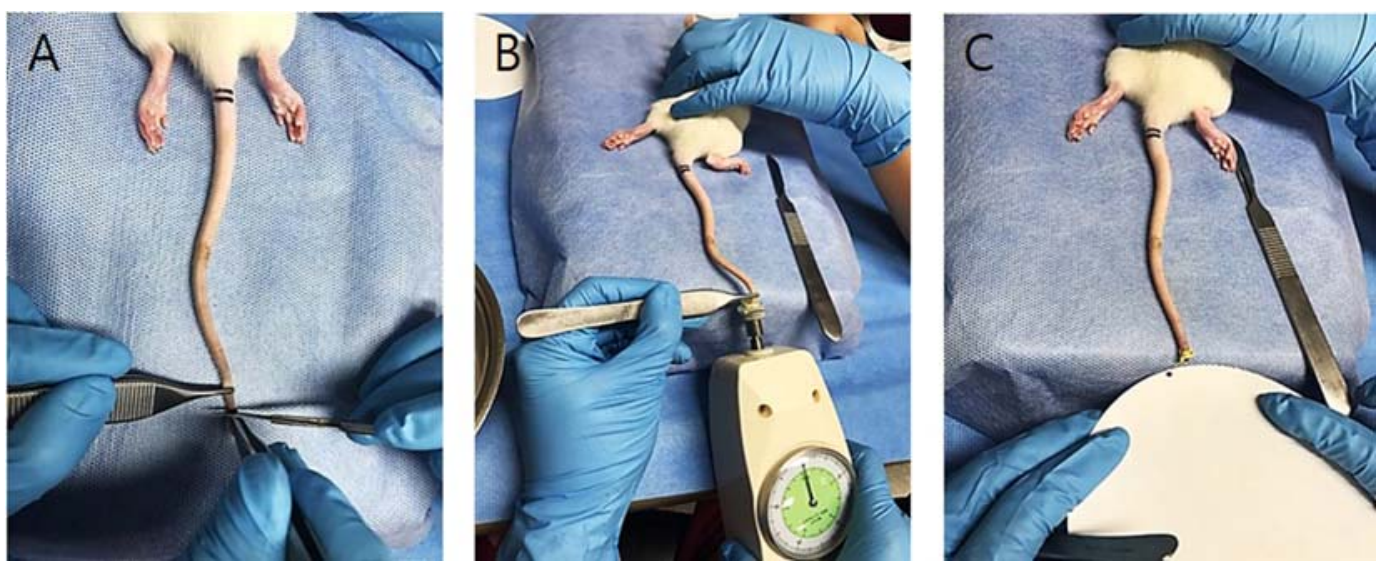

Fig. 1. Evaluation of hemostatic efficacy of three styptics using a rat tail bleeding model. (A) Tails of rats at a diameter of 2 mm were transected. (B) Each test agent $(50 \mathrm{mg}$ ) was applied to the wounds with pressure of $0.1 \mathrm{~N}$ using mechanical push-pull gauge. In the control group, equal compression was applied without any styptic. (C) Wounds were observed for initial hemostasis by blotting with Whatman No. 1 filter paper at intervals of $10 \mathrm{sec}$ for up to $3 \mathrm{~min}$. 
In vitro analysis of the cytotoxicity

Preparation of extracts: Styptic agents were incubated in Roswell Park Memorial Institute (RPMI) 1640 medium (Gibco, USA) supplemented with $10 \%$ fetal bovine serum (FBS, GenKen, USA) and 1\% antibiotic-antimycotic solution (Antianti 100X; Gibco) for $24 \mathrm{~h}$ at $37^{\circ} \mathrm{C}$. The extract was prepared according to the International Standards Organization (ISO) 10993-5 [16] and 10993-12 [18] (ratio of specimen weight to extraction medium volume was $100 \mathrm{mg} / \mathrm{mL}$ ) and designated as $100 \%$. The $100 \%$ extract was serially diluted with the same medium to $1: 10,1: 100$, and $1: 1,000(10 \%$, $1 \%$, and $0.1 \%$, respectively). For cytotoxicity testing, all extracts were centrifuged at $572 \times \mathrm{g}$ for $5 \mathrm{~min}$ and then filtered using a sterile $0.22 \mu \mathrm{m}$ syringe filter.

Cell culture: L-929 mouse fibroblasts (Korean Cell Line Bank, Korea) were grown in RPMI 1640 medium with $10 \%$ FBS and $1 \%$ antibiotic-antimycotic solution in a humidified atmosphere of $5 \% \mathrm{CO}_{2}$ at $37^{\circ} \mathrm{C}$. The cells were subcultured every 2-3 days, seeded in 96-well plates (SPL Life Sciences, Korea) at a density of 10,000 cells $/ 100 \mu \mathrm{L}$ of medium per well, and incubated for $24 \mathrm{~h}$ to allow attachment.

Cell viability (CCK-8 assay): The viability of L-929 cells was detected using the CCK-8 assay (Abbkine, China) according to the manufacturer's recommendations. For treatments, the growth medium was gently removed, and $100 \mu \mathrm{L}$ of the undiluted $(100 \%)$ and three $(10 \%, 1 \%$, and $0.1 \%)$ concentrations of the extracts were added separately to the L-929 cells. Furthermore, $0.9 \%$ normal saline and $1 \%$ sodium hydroxide $(\mathrm{NaOH})$ served as the negative and positive controls, respectively. After a $24 \mathrm{~h}$ exposure, the medium was replaced with fresh medium, and $10 \mu \mathrm{L} \mathrm{CCK}-8$ solution was added to each well, followed by a $2 \mathrm{~h}$ incubation. The optical density (OD) of each well was read at a wavelength of $450 \mathrm{~nm}$ to assess the cell viability using a plate reader (SpectraMax 190; Molecular Devices, USA). The cell viability was calculated as follows:

Cell viability $(\%)=\frac{\mathrm{OD}(\text { experiment })-\mathrm{OD}(\text { blank })}{\mathrm{OD}(\text { control })-\mathrm{OD}(\text { blank })} \times 100$.

\section{Statistical analysis}

All statistical analyses were performed using the SPSS Statistics 24.0 (IBM, USA) for Windows. All data were tested for normality using the Shapiro-Wilk test. Fisher's exact test was performed to identify significant differences between the results of the efficacy of hemostasis. Cell viability data are expressed as means $\pm \mathrm{SD}$, and were analyzed using a oneway analysis of variance (ANOVA) followed by a multiple comparison test using the Tukey honest significant difference post-hoc test to investigate statistically significant differences in cytotoxicity among groups. $P$ values $<0.05$ indicated statistically significant differences for all comparisons.

\section{Results}

\section{Hemostatic efficacy}

The total outcomes of the hemostatic analysis for all the styptic and control groups are shown in Table 1. Initial hemostasis was achieved in 10,10, and 5 rats among the FSC-PO, FSC-G, and FSL-SP rats in each group. No initial hemostasis was observed in the control group. Hemostasis was improved with all styptics compared to the control group $(p<0.01)$. The rate of initial hemostasis in the FSL-SP group

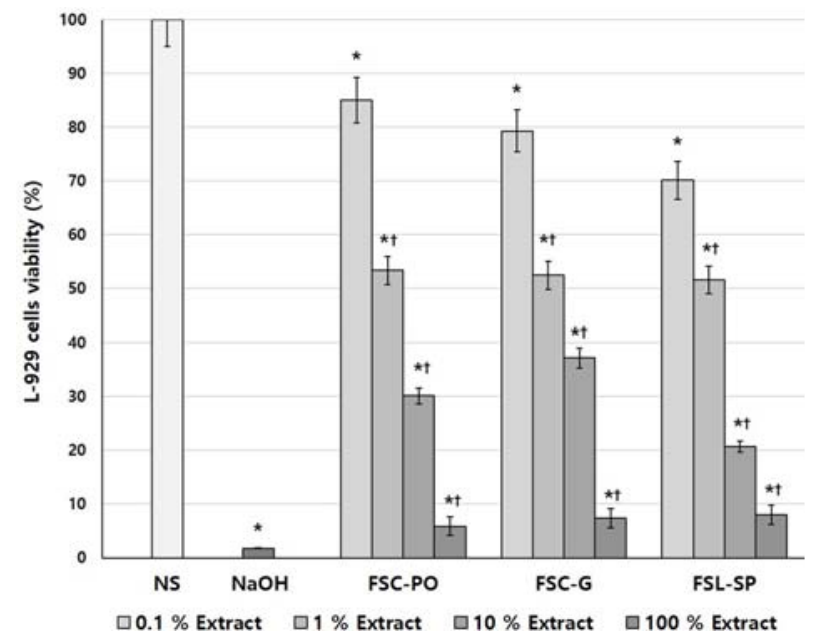

Fig. 2. Viability of L-929 cells exposed to different concentrations of each styptic for $24 \mathrm{~h}$. Viability of all styptic-treated cells was significantly reduced regardless of extract concentration compared to normal saline-treated control group. In each group, dose-dependent cytotoxicity was observed. Negative and positive controls were $0.9 \%$ normal saline and $1 \%$ sodium hydroxide $(\mathrm{NaOH})$, respectively. Data are mean $\pm \mathrm{SD} .{ }^{*}$ Compared with normal saline-treated control group $(p<0.01)$. ${ }^{\dagger}$ Compared with next lower concentration $(p<0.05)$. NS, normal saline.

Table 1. Hemostatic outcomes of styptic treatment for tail bleeding in rats

\begin{tabular}{|c|c|c|c|c|}
\hline Outcome & $\begin{array}{c}\text { FSC-PO } \\
(\mathrm{n}=10)\end{array}$ & $\begin{array}{l}\text { FSC-G } \\
(\mathrm{n}=10)\end{array}$ & $\begin{array}{l}\text { FSL-SP } \\
(\mathrm{n}=10)\end{array}$ & $\begin{array}{l}\text { Control } \\
(\mathrm{n}=10)\end{array}$ \\
\hline Initial hemostasis* & $10 / 10^{\mathrm{ab}}$ & $10 / 10^{\mathrm{ab}}$ & $5 / 10^{\mathrm{a}}$ & $0 / 10$ \\
\hline Recurrent hemorrhage $^{\dagger}$ & $1 / 10^{\mathrm{a}}$ & $0 / 10^{\mathrm{a}}$ & $4 / 10$ & $7 / 10$ \\
\hline
\end{tabular}

Data were analyzed by Fisher's exact test compared with ${ }^{\mathrm{a}}$ control $(p<0.05)$ and ${ }^{\mathrm{b}} \mathrm{FSL}-\mathrm{SP}(p<0.05)$. FSC-PO, powder containing ferric subsulfate and chitosan; FSC-G, gel containing ferric subsulfate and chitosan; FSL-SP, soaked pad containing ferric subsulfate and lidocaine. *Initial hemostasis is considered to occur when bleeding stops within 3 min after compression. ${ }^{\dagger}$ Recurrent hemorrhage is considered to occur when re-bleeding is observed when the wound is irrigated with saline $3 \mathrm{~min}$ after complete hemostasis. 
Table 2. L-929 cell viability values (mean \pm SD) of cell counting kit-8 assay

\begin{tabular}{lcc}
\hline \hline \multicolumn{1}{c}{ Groups } & $\begin{array}{c}\text { Concentration } \\
(\%)\end{array}$ & $\begin{array}{c}\text { Percentage of viable cell } \\
(\%)^{*}\end{array}$ \\
\hline Normal saline & 0.9 & $100 \pm 3.81$ \\
$\mathrm{NaOH}$ & 1 & $1.76 \pm 0.66^{\mathrm{a}}$ \\
& 100 & $5.88 \pm 2.73^{\mathrm{a}, \mathrm{b}}$ \\
FSC-PO & 10 & $30.13 \pm 7.83^{\mathrm{a}, \mathrm{b}}$ \\
& 1 & $53.33 \pm 6.64^{\mathrm{a}, \mathrm{b}}$ \\
& 0.1 & $85.04 \pm 4.57^{\mathrm{a}}$ \\
FSC-G & 100 & $7.34 \pm 2.98^{\mathrm{a}, \mathrm{b}}$ \\
& 10 & $37.20 \pm 5.42^{\mathrm{a}, \mathrm{b}}$ \\
& 1 & $52.45 \pm 8.58^{\mathrm{a}, \mathrm{b}}$ \\
FSL-SP & 0.1 & $79.33 \pm 7.81^{\mathrm{a}}$ \\
& 100 & $8.01 \pm 2.20^{\mathrm{a}, \mathrm{b}}$ \\
& 10 & $20.64 \pm 6.56^{\mathrm{a}, \mathrm{b}, \mathrm{c}}$ \\
& 0.1 & $51.58 \pm 3.55^{\mathrm{a}, \mathrm{b}}$ \\
& 1 & $70.12 \pm 8.83^{\mathrm{a}, \mathrm{d}}$ \\
\hline
\end{tabular}

*Data are mean \pm SD. It was analyzed Tukey honest significant difference test compared with anormal saline-treated control group $(p<0.01)$, " next lower concentration $(p<0.05)$, ${ }^{\mathrm{c}} \mathrm{FSC}-\mathrm{G} 10 \%$ extract $(p<0.05)$, and ${ }^{\mathrm{d}}$ FSC-PO $0.1 \%$ extract $(p<0.05)$.

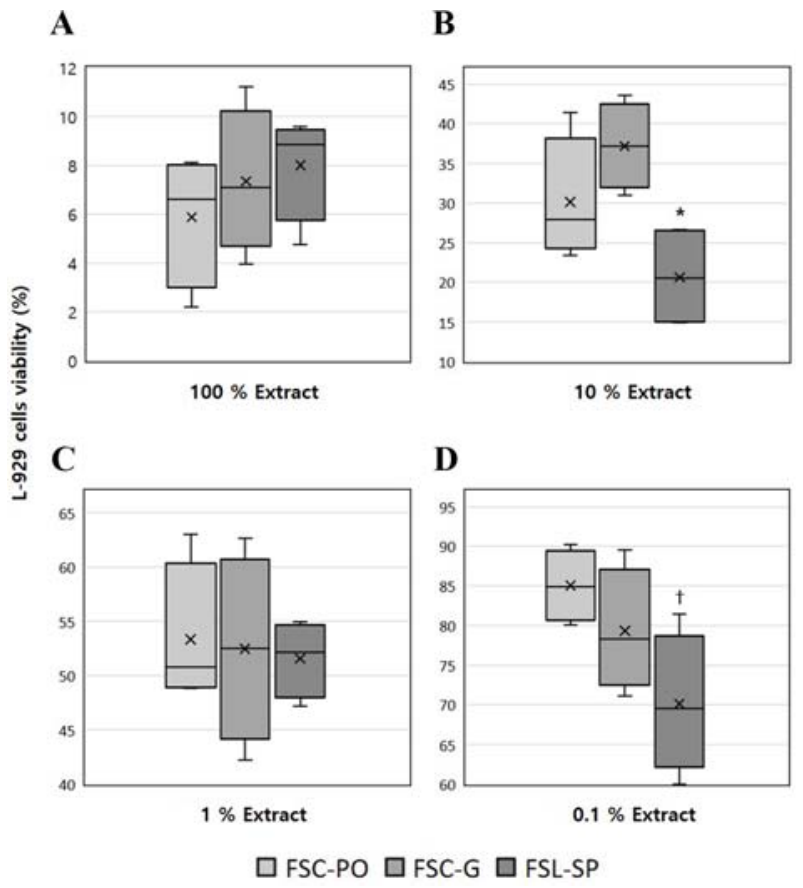

Fig. 3. Viability of L-929 cells exposed to different concentrations of each styptic for $24 \mathrm{~h}$. The same concentrations of styptic extract significantly reduced cell viability FSL-SP compared to FSC-G $10 \%$ extract (B) and FSC-PO $0.1 \%$ extract (D). Data are means \pm SD. There was no significant difference among the styptics at $100 \%$ extract (A) and $1 \%$ extract (C) $(p>0.05)$. *Compared with FSC-G $10 \%$ extract $(p<0.05)$. Compared with FSC-PO $0.1 \%$ extract $(p<0.05)$. was significantly lower than that in the FSC-PO and FSC-G groups $(p=0.033)$. Recurrent hemorrhage after saline irrigation developed in one, four, and seven rats in the FSC-PO, FSL-SP, and control groups, respectively. All rats in the FSC$\mathrm{G}$ treatment group did not develop recurrent hemorrhage after irrigation $(n=10)$. Hemostasis was significantly maintained in the FSC-PO and FSC-G groups compared with the control group ( $p=0.02$ and $p<0.01$, respectively).

\section{Cell viability}

The results of the effects of various concentrations of FSCPO, FSC-G, and FSL-SP on the L-929 cells are displayed in Table 2. As compared with the normal saline-treated group, all the styptic-treated cells showed a significant reduction in viability $(p<0.01$, Fig. 2$)$. The percentages of viable cells varied from $85.04 \%$ to $5.88 \%, 79.33 \%$ to $7.34 \%$, and $70.12 \%$ to $8.01 \%$ in the FSC-PO, FSC-G, and FSL-SP groups, respectively depending on the concentrations. All test agents induced dose-dependent cytotoxicity against L-929 cells ( $p<$ 0.05 , Fig. 2). At the same concentration, the percentage of viable cells in the FSL-SP was significantly lower than that in the FSC-G $10 \%$ extract $(p=0.016)$ and FSC-PO $0.1 \%$ extract ( $p=0.042$, Fig. 3).

\section{Discussion}

In the present study, the three ferric subsulfate-containing styptics tested effectively ameliorated hemorrhage in a rat tail bleeding model. Since the French pharmacist Leon Monsel pioneered the discovery of the styptic qualities of ferric subsulfate in 1852, ferric subsulfate has been used as a coagulative and hemostatic agent for minor surgical procedures in dermatology, dentistry, and gynecology [12, 37]. Although the exact hemostatic mechanism of ferric subsulfate is still controversial, it is believed to be due to the denaturation and agglutination of blood proteins by ferric ions [29]. The reaction of blood with ferric and sulfate ions and the acidic $\mathrm{pH}$ of ferric subsulfate solution result in the agglutination of blood proteins, which then form plugs that occlude the capillary orifices [27, 29].

The hemostatic efficacy of ferric subsulfate solution can be augmented by increasing its viscosity [25, 32]. Kuwahara et al. [25] stated that thicker material enhanced coagulation and control of wounds created during dermatologic surgery than thinner material did, and recommended leaving the container of ferric subsulfate solution open to create a thick paste over time. In the present study, three styptics were used in different formulations, and FSL-SP was soaked in a runny solution that showed the lowest viscosity among the three styptic agents when applied to the wounds. FSL-SP showed less efficacy than FSC-PO and FSC-G did in controlling initial hemorrhage. This result supports the previous study by Kuwahara et al. [25] showing that the hemostatic efficacy of ferric subsulfate is viscosity-dependent.

In this study, the styptics containing chitosan were effec- 
tive in achieving and maintaining hemostasis. The hemostatic properties of chitosan involve strong hemagglutination caused by its protonated amine groups that attract red blood cells as well as vasoconstriction [34]. Chitosan also adsorbs fibrinogen and plasma proteins, which enhances platelet aggregation [34]. Unlike other hemostatic agents, chitosan does not require the normal hemostatic pathway and continues to function even when anticoagulants such as heparin are present [30]. Numerous studies have demonstrated the effectiveness of chitosan as a hemostatic agent in controlling hemorrhage from peritoneal abrasions, splenic lacerations, and lingual injury $[7,13,22]$. In this study, the difference in hemostatic efficacy between FSC-PO, FSC-G, and FSL-SP could be explained by the chitosan content that enhances hemostatic property in addition to the viscosity of the hemostatic agent. In addition, FSC-PO and FSC-G were effective in maintaining hemostasis even after blood clots had been washed away by the saline solution, which could be explained by the hemostatic action of chitosan, including mechanical occlusion of direct vasoconstriction.

The CCK-8 assay detects viable cells by assessing the activity of mitochondrial succinate dehydrogenases based on the formation of formazan dye [8]. As the cells lose viability (metabolic activity) and mitochondrial function decreases, the ability of CCK- 8 to convert the tetrazolium salt to the formazan product decreases [33]. Mitochondrial succinate dehydrogenase is sensitive to local changes in ion concentrations and ion flux [33]. Therefore, different concentrations of chemicals and chemical mixtures have been used to estimate the cytotoxicity in various studies $[20,33]$. In this study, the cytotoxicity of the three styptics was estimated at four different concentrations, and various toxicity results in L-929 cells were obtained.

Despite the advantage of hemostasis, complications of using ferric subsulfate including erythema, dermal fibrosis, and ferrugination (permanent deposition of ferric salts creating a gray to brown dyspigmentation at the site of application) have been reported $[3,32,35]$. Ferric subsulfate may increase melanocyte activity, resulting in postinflammatory hyperpigmentation, and increase the risk of infection [3, 14, 26, 35]. Additionally, ferric subsulfate damages bone and delays wound healing if left in situ [19, 27]. Although several complications were reported, cytotoxicity assessments of styptics containing ferric subsulfate have not been performed.

In this study, all the styptics showed dose-dependent cytotoxicity against L-929 cells. Although the exact mechanism of the cytotoxicity of styptics has not been elucidated, $\mathrm{pH}$ is considered an important factor. Low extracellular $\mathrm{pH}$ increases the influx of lactate, and the intracellular acidosis proceeds [4]. Increased intracellular lactate concentration may have a negative effect on mitochondrial energy production and the cell function [4]. Several publications reported low $\mathrm{pH}$ of ferric subsulfate solution approximately between $\mathrm{pH} 1$ and $\mathrm{pH} 2$ $[29,36]$. In the present study, the acidic property of ferric subsulfate seemed to induce the cytotoxicity, although $\mathrm{pH}$ measurement of the extract is required.

FSL-SP contains additional lidocaine that is a commonly used local anesthetics for pain management [17]. Recently, questions about the safety of local anesthetics have been raised [17]. Chu et al. [9] reported the extreme toxicity of bupivacaine on human chondrocytes in vitro. Miyazaki et al. [31] reported that lidocaine decreased the viability and proteoglycan production of bovine articular chondrocytes in a concentration-dependent manner. Lidocaine exhibited both time- and dose-dependent toxicity on cultivated mature human chondrocytes [17]. Although the exact mechanism of it's local anesthetic toxicity has not been clarified, lidocaine may affect mitochondrial energetics, resulting in mitochondrial damage that can induce either apoptosis or necrosis with less severe injuries leading to apoptosis $[15,23]$. In this study, the cell viability following FSL-SP treatment was decreased compared to that of cells treated with FSC-G $10 \%$ and FSCPO $0.1 \%$ extracts, respectively. The potential toxicity of lidocaine could contribute to the lower viability of FSL-SPtreated cells than cells treated with other styptics.

In conclusion, three ferric subsulfate- and chitosan-based styptics were found to be effective in treating hemorrhage in a rat tail bleeding model. As FSC-PO and FSC-G appeared to be efficacious in achieving and maintaining hemostasis, their uses can be recommended. However, the cytotoxicity of all the styptics against L-929 mouse fibroblasts increased in a dose-dependent manner. Therefore, the hemostatic benefits of styptics must be balanced against the clinical significance of their cytotoxicity.

\section{References}

1. Alam HB, Uy GB, Miller D, Koustova E, Hancock T, Inocencio R, Anderson D, Llorente O, Rhee P. Comparative analysis of hemostatic agents in a swine model of lethal groin injury. J Trauma 2003, 54, 1077-1082.

2. Anitha A, Rani VVD, Krishna R, Sreeja V, Selvamurugan N, Nair SV, Tamura H, Jayakumar R. Synthesis, characterization, cytotoxicity and antibacterial studies of chitosan, $O$ carboxymethyl and $\mathrm{N}, \mathrm{O}$-carboxymethyl chitosan nanoparticles. Carbohydr Polym 2009, 78, 672-677.

3. Armstrong RB, Nichols J, Pachance J. Punch biopsy wounds treated with Monsel's solution or a collagen matrix. A comparison of healing. Arch Dermatol 1986, 122, 546-549.

4. Borregaard N, Herlin T. Energy metabolism of human neutrophils during phagocytosis. J Clin Invest 1982, 70, 550557.

5. Brooks J. Coagulopathies and thrombosis. In: Ettinger SJ, Felman EC (eds.). Textbook of Veterinary Internal Medicine: Disease of the Dog and Cat. 5th ed. pp. 1829-1841, WB Saunders, Philadelphia, 2000.

6. Broze GJ Jr, Yin ZF, Lasky N. A tail vein bleeding time model and delayed bleeding in hemophiliac mice. Thromb Haemost 2001, 85, 747-748.

7. Chan MW, Schwaitzberg SD, Demcheva M, Vournakis J, Finkielsztein S, Connolly RJ. Comparison of poly- $N$-acetyl glucosamine (P-GlcNAc) with absorbable collagen (Actifoam), 
and fibrin sealant (Bolheal) for achieving hemostasis in a swine model of splenic hemorrhage. J Trauma 2000, 48, 454458.

8. Chang Y, Yang ST, Liu JH, Dong E, Wang Y, Cao A, Liu Y, Wang H. In vitro toxicity evaluation of graphene oxide on A549 cells. Toxicol Lett 2011, 200, 201-210.

9. Chu CR, Izzo NJ, Coyle CH, Papas NE, Logar A. The in vitro effects of bupivacaine on articular chondrocytes. J Bone Joint Surg Br 2008, 90, 814-820.

10. Donahue SM, Otto CM. Thromboelastography: a tool for measuring hypercoagulability, hypocoagulability, and fibrinolysis. J Vet Emerg Crit Care (San Antonio) 2005, 15, 9-16.

11. Epstein E, Maibach HI. Monsel's solution. History, chemistry and efficacy. Arch Dermatol 1964, 90, 226-228.

12. Fischer DE. Tissue management: a new solution to an old problem. Gen Dent 1987, 35, 178-182.

13. Fukasawa M, Abe H, Masaoka T, Orita H, Horikawa H, Campeau JD, Washio M. The hemostatic effect of deacetylated chitin membrane on peritoneal injury in rabbit model. Surg Today 1992, 22, 333-338.

14. Howe N, Cherpelis B. Obtaining rapid and effective hemostasis. Part I. Update and review of topical hemostatic agents. J Am Acad Dermatol 2013, 69, 659.e1-659.e17.

15. Irwin W, Fontaine E, Agnolucci L, Penzo D, Betto R, Bortolotto S, Reggiani C, Salviati G, Bernardi P. Bupivacaine myotoxicity is mediated by mitochondria. J Biol Chem 2002, 277, 12221-12227.

16. International Organization for Standardization (ISO). ISO 10993-5:2009. Biological evaluation of medical devices-Part 5: Tests for in vitro cytotoxicity. ISO, Geneva, 2009.

17. Jacobs TF, Vansintjan PS, Roels N, Herregods SS, Verbruggen G, Herregods LL, Almqvist KF. The effect of Lidocaine on the viability of cultivated mature human cartilage cells: an in vitro study. Knee Surg Sports Traumatol Arthrosc 2011, 19, 1206-1213.

18. Jansen T, Wallin RF. A practical guide to ISO 10993-12: sample preparation and reference materials. North American Science Associates, Northwood, 1998.

19. Jeansonne BG, Boggs WS, Lemon RR. Ferric sulfate hemostasis: effect on osseous wound healing. II. With curettage and irrigation. J Endod 1993, 19, 174-176.

20. Jiao G, He X, Li X, Qiu J, Xu H, Zhang N, Liu S. Limitations of MTT and CCK-8 assay for evaluation of graphene cytotoxicity. RSC Adv 2015, 5, 53240-53244.

21. Kheirabadi BS, Edens JW, Terrazas IB, Estep JS, Klemcke HG, Dubick MA, Holcomb JB. Comparison of new hemostatic granules/powders with currently deployed hemostatic products in a lethal model of extremity arterial hemorrhage in swine. J Trauma 2009, 66, 316-328.

22. Klokkevold PR, Fukayama H, Sung EC, Bertolami CN. The effect of chitosan (poly-N-acetyl glucosamine) on lingual hemostasis in heparinized rabbits. J Oral Maxillofac Surg 1999, 57, 49-52.
23. Kroemer G, Dallaporta B, Resche-Rigon M. The mitochondrial death/life regulator in apoptosis and necrosis. Annu Rev Physiol 1998, 60, 619-642.

24. Kunio NR, Riha GM, Watson KM, Differding JA, Schreiber MA, Watters JM. Chitosan based advanced hemostatic dressing is associated with decreased blood loss in a swine uncontrolled hemorrhage model. Am J Surg 2013, 205, 505-510.

25. Kuwahara RT, Craig SR, Amonette R. More on Monsel's solution. Dermatol Surg 2000, 26, 979-980.

26. Larson PO. Topical hemostatic agents for dermatologic surgery. J Dermatol Surg Oncol 1988, 14, 623-632.

27. Lemon RR, Steele PJ, Jeansonne BG. Ferric sulfate hemostasis: effect on osseous wound healing. I. Left in situ for maximum exposure. J Endod 1993, 19, 170-173.

28. Lönnroth EC, Dahl JE. Cytotoxicity of liquids and powders of chemically different dental materials evaluated using dimethylthiazol diphenyltetrazolium and neutral red tests. Acta Odontol Scand 2003, 61, 52-56.

29. Miller DT, Roque DM, Santin AD. Use of Monsel solution to treat obstetrical hemorrhage: a review and comparison to other topical hemostatic agents. Am J Obstet Gynecol 2015, 212, 725-735.

30. Millner R, Lockhart AS, Marr R. Chitosan arrests bleeding in major hepatic injuries with clotting dysfunction: an in vivo experimental study in a model of hepatic injury in the presence of moderate systemic heparinisation. Ann R Coll Surg Engl 2010, 92, 559-561.

31. Miyazaki T, Kobayashi S, Takeno K, Yayama T, Meir A, Baba H. Lidocaine cytotoxicity to the bovine articular chondrocytes in vitro: changes in cell viability and proteoglycan metabolism. Knee Surg Sports Traumatol Arthrosc 2011, 19, 1198-1205.

32. Palm MD, Altman JS. Topical hemostatic agents: a review. Dermatol Surg 2008, 34, 431-445.

33. Putnam KP, Bombick DW, Doolittle DJ. Evaluation of eight in vitro assays for assessing the cytotoxicity of cigarette smoke condensate. Toxicol In Vitro 2002, 16, 599-607.

34. Rao SB, Sharma CP. Use of chitosan as a biomaterial: studies on its safety and hemostatic potential. J Biomed Mater Res 1997, 34, 21-28.

35. Sawchuk WS, Friedman KJ, Manning T, Pinnell SR. Delayed healing in full-thickness wounds treated with aluminum chloride solution: a histologic study with evaporimetry correlation. J Am Acad Dermatol 1986, 15, 982-989.

36. Spitzer M, Chernys AE. Monsel's solution-induced artifact in the uterine cervix. Am J Obstet Gynecol 1996, 175, 12041207.

37. Wagner WR, Pachence JM, Ristich J, Johnson PC. Comparative in vitro analysis of topical hemostatic agents. J Surg Res 1996, 66, 100-108.

38. Whalen J, Tuman KJ. Monitoring hemostasis. Int Anesthesiol Clin 1996, 34, 195-213. 